\title{
ist \\ As muitas faces do altruísmo: pressões seletivas e grupos humanos
}

\author{
Lorenzo BARAVALLE
}

\begin{abstract}
is
RESUMO

No âmbito do debate sobre as unidades envolvidas nos processos seletivos, a controvérsia sobre a possibilidade de comportamentos genuinamente altruístas tem um lugar destacado. Partindo de uma posição declaradamente pluralista, discutir-se-ão, neste artigo, algumas questões relevantes para esse tópico. Em primeiro lugar, o altruísmo será concebido como uma propriedade fenotípica dos grupos biológicos, e não apenas de seus membros. Essa caraterização levará, em um segundo momento, à discussão sobre a relação entre grupos em sociedades complexas, como é o caso das sociedades humanas. Nesse contexto, será esboçado um modelo sobre como os comportamentos altruístas e os comportamentos egoístas se solapam em níveis diferentes das dinâmicas sociais. Finalmente, será sugerido um método de análise dirigido a determinar quais forças evolutivas entram em jogo, e sobre que tipo de comportamento, em casos empíricos concretos.
\end{abstract}

Palavras-chave • Egoísmo. Altruísmo. Interatuantes. Unidades de seleção. Populações.

\section{INTRODUÇÃO}

No presente artigo, serão discutidas algumas questões relacionadas com o debate sobre as unidades de seleção em biologia evolutiva, e sua importância será estendida ao âmbito das culturas humanas. Em particular, será tematizada a dicotomia egoísmo/ altruísmo, que caracteriza a possibilidade, no contexto biológico, de considerar diferentes níveis de complexidade populacional como relevantes nos processos seletivos e que, no contexto social humano, vê-se enriquecida por considerações de caráter linguístico e psicológico. A finalidade última do trabalho é mostrar como um progressivo afinamento das ferramentas conceituais da análise evolucionária permite lançar luz também sobre domínios que parecem irredutíveis a ela. Com isso, não quero dizer que seja possível reduzir, em algum sentido corrente do termo, o desenvolvimento das culturas (com suas próprias dinâmicas e variações históricas) a um mecanismo seletivo. Nem considero que, no estado atual, seja correto chamar de científicos os empreendimentos teóricos que visam à identificação (total ou parcial) entre os dois processos 
(cf. Munz, 1993; Dennett, 1995; Blackmore, 1999). Contudo, acredito que muitos fenômenos culturais humanos constituam modelos para certas interpretações da teorias da seleção natural (cf. Cavalli-Sforza \& Feldman, 1981; Boyd \& Richerson, 1985; Bohem, 1993; Jablonka \& Lamb, 2005). Em outras palavras, não é minha intenção dizer nada sobre o que é a "seleção cultural", se é que existe realmente algum mecanismo desse tipo, comparável por abrangência e universalidade com a seleção natural. Apenas quero mostrar que a aplicação de certas conceitualizações próprias da biologia evolutiva aplicam-se com proveito aos contextos culturais. Espero que o sentido dessas afirmações fique mais claro depois da leitura do texto.

Antes de entrar na discussão, é preciso assinalar alguns outros obstáculos conceituais recorrentes, para assim evitar possíveis equívocos. O primeiro tem a ver com um mal entendido frequente, na hora de determinar exatamente o objeto da discussão. O debate sobre as unidades de seleção, cujas origens correspondem de alguma maneira ao nascimento mesmo da moderna teoria evolucionaria, conheceu uma fase de grande animação acerca do estatuto, por assim dizer, "ontológico" das pressões evolutivas, desde a publicação de Wynne-Edwards (1962), a favor da existência de uma genuína seleção de grupo, a qual suscitou as críticas de Williams (1966) e o estabelecimento de uma "ortodoxia reducionista" com Dawkins (1976, 1982), até chegar a um novo equilíbrio com os trabalhos de Sober e Wilson (1994; 2000 [1998]). ${ }^{2}$ Estes últimos, a partir do artigo pioneiro de Hamilton (1975), e mostrando algumas confusões presentes nos modelos de seleção de parentesco (cf. Hamilton, 1963; Maynard-Smith, 1964), reabilitaram a noção de seleção de grupo, embora em um sentido diferente daquele defendido por Wynne-Edwards. Sem entrar aqui nos detalhes (que serão discutidos no texto), podemos dizer que o artigo e o livro de Sober e Wilson formam parte de um conjunto heterogêneo de textos (cf., por exemplo, Lewontin, 1970; Hull, 1980; Sterelny \& Kitcher, 1988; Sober, 1996 [1993]; Lloyd, 1994; Brandon, 1996), cronologicamente contemporâneos ao mainstream reducionista, que advogavam por um maior pluralismo com respeito à questão das unidades de seleção e pretendiam, assim, deslocar os termos do debate. Finalmente, nos últimos 20 anos, e muito embora no seu interior convivam posições por vezes distantes e em contraste entre si, como, por exemplo, acerca da caracterização dos processos seletivos em termos instrumentalistas (cf. Sterelny \&

1 A posição "reducionista" de Dawkins deve ser entendida em um sentido circunscrito aos elementos causais potencialmente envolvidos nos processos evolutivos. Ela estabelece que somente o gene cumpre os requisitos para ser propriamente considerado como unidade de seleção. De acordo com os modelos elaborados nessa tradição, os níveis superiores de complexidade biológica (principalmente os organismos) jogam um papel secundário e derivado, isto é, limitam-se a favorecer a expressão diferencial de certos genes (cf. Sterelny \& Kitcher, 1988).

2 O texto de 1994, tem como primeiro autor D. S. Wilson mas, por comodidade, referir-me-ei sempre, ao longo do artigo, ao trabalho de "Sober e Wilson", já que é essa a ordem dos autores do texto, mais completo, de 1998. 
Kitcher, 1988) ou realistas (cf. Shanahan, 1996; Sober \& Wilson, 2000 [1998]), a tendência pluralista foi ganhando cada vez mais aceitação, se não entre os biólogos (cf., por exemplo, Ridley, 2004, cap. 11), ao menos entre os filósofos (cf. Diéguez, 2012, cap. 10). A coletânea editada por Keller (1999) coloca-se, com suas próprias peculiaridades e idiossincrasias, dentro dessa tendência. De particular interesse neste contexto, a contribuição de Reeve e Keller (cap. 1) traça com claridade a distinção entre um antes e um depois no debate sobre as unidades da seleção. Nos textos "clássicos", "a questão [é] qual é a "verdadeira' unidade fundamental de seleção". Essa questão articulou-se em duas linhas principais de debate: "(a) se os genes, ou os indivíduos, são melhores candidatos como verdadeiras unidades da seleção, e (b) se os grupos de indivíduos podem ser unidades de seleção". Assumindo uma posição pluralista, esses problemas, na nova fase do debate, perdem importância e as questões relevantes vêm a ser outras, a saber, "(1) como a seleção natural entre unidades biológicas de mais baixo nível (por exemplo, organismos) cria unidades de mais alto nível (por exemplo, sociedades), e (2) dado que existem múltiplos níveis, como a seleção natural em um nível biológico afeta a seleção em níveis mais baixos ou mais altos" (Reeve \& Keller, 1999, p. 3). Adotando essa perspectiva, no presente artígo ocupar-me-ei apenas de duas subquestões. A primeira, relacionada com (1), é: como as forças evolutivas vinculam os organismos dentro de unidades sociais? Ou, em outras palavras, por que os organismos são levados, em determinadas circunstâncias, a subordinar seus próprios interesses aos da comunidade? A resposta será: devido ao potencial adaptativo dos comportamentos altruístas. A segunda questão, relacionada com (2), é: como interagem distintas forças e interesses, distribuídos dentro de uma sociedade humana em vários níveis (indivíduos, famílias, grupos sociais), para formar estruturas tão complexas? Nesse caso, a resposta não será nem tão simples nem tão direta. Meu objetivo será apenas o de mostrar como uma interpretação evolucionária pode ser útil para compreender certas tendências sociais.

Outro obstáculo conceitual, quando se deseja considerar evolutivamente certos comportamentos, pode ser representado pela carga semântica de termos como "altruísmo" e "egoísmo". Por um lado, Sewall Wright (1980, p. 84,o) refere que o primeiro a usar o termo "altruísmo" em biologia evolutiva, se referindo a um fenótipo "que contribui à vantagem do grupo a expensas de si mesmo", é Haldane (1932). Pelo outro, o egoísmo do replicante genético de Dawkins (1976), que "usa" o veículo do organismo para otimizar a difusão de suas cópias, é sem dúvida o exemplo mais célebre de como o segundo termo tem sido empregado em biologia. Algum leitor poder-se-ia queixar pelo uso descontextualizado desses conceitos, com respeito aos domínios tradicionais da ética e, talvez, da psicologia. Concordo com ele que, às vezes, os biólogos evolutivos e os filósofos da biologia são muito liberais no uso de palavras cujo conteúdo não é neu- 
tro (admitindo que essas palavras existam, poderíamos perguntar se não teria sido melhor Haldane usar, por exemplo, o termo "cooperação"). Alguns biólogos preferem, de fato, falar de cooperação, sobretudo, ao referirem-se a microrganismos que interagem de maneira mutuamente coordenada ou ao usar como modelo a teoria dos jogos. A escolha de manter o termo "altruísta" deve-se à preferência dada a esse termo por parte dos autores envolvidos no debate, o que não é casual (cf. Sober \& Wilson, 2000 [1998], p. 65). Contudo, não considero que, uma vez que o significado das expressões seja fixado, surjam mais inconvenientes. Por outro lado, poder-se-ia questionar o direito, por parte da ética e da psicologia, de reclamar essas noções como suas próprias, já que não me parece que essas áreas do conhecimento tenham alcançado um acordo extenso e duradouro sobre seu significado.

Um último obstáculo para a clareza da discussão é o uso nem sempre claro de uma série de conceitos comumente empregados no debate, muitas vezes com nuances diferentes. Por isso, dedicarei a primeira seção a uma breve elucidação dos mesmos.

\section{RePLICAdoREs, veículos E INTERATUANTES}

Um dos méritos inegáveis das primeiras obras de Richard Dawkins (1976, 1982) é ter fornecido um vocabulário popular aos termos do debate sobre as unidades de seleção. Em particular, devemos a ele a representação do gene como replicador, unidade básica (e única) da seleção, potencialmente imortal graças à capacidade de produzir cópias praticamente perfeitas, e a redução do organismo a veículo, que "protege os replicadores, e que pode ser visto como a máquina programada para preservar e propagar os replicadores que a dirigem" (Dawkins, 1982, p. 295). Hull considera essa terminologia inadequada para dar conta da possibilidade de seleção em múltiplos níveis e, assim, propõe algumas mudanças, pequenas mas substanciais. Em primeiro lugar, Hull libera-se do pressuposto reducionista, que identifica a capacidade replicante do gene com a propriedade de ser $a$ unidade básica da seleção natural, e caracteriza o replicador simplesmente como "uma entidade que transmite diretamente sua estrutura na replicação" (Hull, 1980, p. 318). Em segundo lugar, substitui o termo "veículo" por "interatuante" (interactor), mais neutro e adequado para representar uma imagem dos processos seletivos mais articulada. Interatuante é qualquer produto do mecanismo de transmissão de replicadores que exibe um fenótipo e que sofre, portanto, uma influência direta do ambiente. ${ }^{3}$ Dado que os processos seletivos agem principalmente so-

3 “[o interatuante] é uma entidade que interage diretamente como um todo coeso com seu ambiente, de maneira tal que a replicação seja diferencial” (Hull, 1980, p. 318). Quanto um interatuante deva ser coeso para poder ser consi- 
bre fenótipos, que são as entidades capazes de exibir adaptações, Hull argumenta que deveríamos considerar como unidades da seleção todas as entidades que mostram as caraterísticas próprias de um interatuante, e não os replicadores.

Os termos "replicador" e "interatuante" não são (usando uma linguagem kripkiana) designadores rígidos. Eles não denotam uma única referência. O fato de que o gene, na grande maioria dos modelos de seleção natural, ocupe o lugar do replicador, não implica que isso seja necessário. Brandon (1996) considera que é possível esboçar uma hierarquia de níveis de complexidade biológica na qual todos os elementos (gene, organismo, grupo, espécie e clado) podem figurar como interatuantes, e ao menos alguns deles como replicadores (gene, grupo, espécie e clado). Obviamente, trata-se de uma possibilidade teórica, que deve ser confrontada com modelos empíricos. Algumas das combinações expostas por Brandon (por exemplo, organismo-gene, espécieespécie ou clado-clado, onde o primeiro termo é o interatuante e o segundo, o replicador) não interessam aqui, nem serão discutidas; o par grupo-gene-responsável pela seleção intradêmica (isto é, a seleção de caracteres transmitidos por via genética dentro do mesmo grupo) - será discutido com relação aos modelos reducionistas. Finalmente, Brandon contempla a combinação grupo-grupo, considerada de primária importância para dar conta da seleção interdêmica (ou seja, a seleção de caracteres que favorecem um grupo frente a outros grupos), que será tratada com mais detalhe.

No elenco de Brandon parece faltar uma combinação à primeira vista interessante, dadas as coordenadas do debate apresentadas na introdução; trata-se do par organismo-grupo. Isso é natural, dado que comumente não se considera que o organismo possa ser um replicador. O organismo não transmite diretamente sua estrutura. "Na reprodução sexual, o genoma do organismo é quebrado, devido à segregação e à recombinação. Portanto, apenas partes do genoma reproduzem sua estrutura direta e acuradamente" (Brandon, 1996, p. 136-7). Obviamente, o caso das espécies que se reproduzem assexuadamente é distinto, dado que o organismo é replicado junto com todo seu material genético. Tendo presente essas ressalvas, é minha intenção mostrar, contudo, que no contexto social humano - e conforme os modelos de Cavalli-Sforza e Feldman (1981), Boyd e Richerson (1985), Richerson e Boyd, 2006 [2005] -, podemos considerar o organismo como um transmissor de informação cultural independente de sua dotação genética. Nesse sentido, ele preencheria os requisitos fundamentais para ser um replicador.

derado como tal não é uma questão trivial. A posição de Hull (1980) é relativamente conservadora (e próxima a Dawkins) mas, conforme caracterizações posteriores (cf. Hull, 1998), podemos incluir os grupos entre os candidatos interatuantes, devido a sua extensão espaço-temporal, certas relações de parentesco e a pertença a um mesmo nicho ecológico. 
Esclarecido isso, vamos discutir uma última questão preliminar. Lloyd (2007) apresenta quatro perguntas, relacionadas com o problema das unidades de seleção, de alguma maneira transversais com respeito às que vimos ser assinaladas por Reeve e Keller.

- O problema do interatuante. Qual é a entidade cujo fenótipo se expõe diretamente às pressões seletivas?

- O problema do replicador. Qual é a entidade cuja estrutura permite o processo de transmissão?

- O problema do beneficiário. Quem se beneficia, a longo prazo, do processo seletivo?

- O problema de quem manifesta a adaptação. Em que nível se manifesta a adaptação (entendida como "avanço de engenharia" - por exemplo, maior tamanho, chifres, asas, garras etc. -, e não como simples produto da seleção)?

O que, em ocasiões, pode gerar perplexidade com relação à possibilidade de considerar os grupos como interatuantes é que se acredita, erroneamente, que isso implique uma afirmação acerca das últimas duas perguntas. Mas a resposta aos quatro quesitos apresentados por Lloyd pode não ser a mesma. $\mathrm{O}$ fato de que exista pressão seletiva com respeito a um determinado interatuante coletivo (que se manifesta como um fenótipo suscetível de ser selecionado) não implica que a adaptação se manifeste no mesmo nível, nem que o beneficiário último da seleção seja o grupo. De fato, Lloyd considera que o beneficiário da seleção é, em um sentido próprio, sempre o gene; ${ }^{4}$ enquanto as adaptações manifestam-se geralmente no nível dos organismos. Aparentemente, isso contradiz a interpretação clássica, proposta por Williams (cf. 1966) e parcialmente aceita também por Sober e Wilson (cf. 1994; 1998), segundo a qual não devemos postular adaptação em um nível sem que exista um processo seletivo atuando naquele mesmo nível. Inversamente, sempre seguindo essa interpretação, se observamos adaptações em um determinado nível, isso implicaria que a seleção atuou naquele mesmo nível, e não em outro.

Conforme a análise de Lloyd, a incompatibilidade entre as perspectivas é apenas fruto de uma confusão já parcialmente relevada por Wright (1980) entre dois significados de "adaptação", a saber, adaptação como produto da seleção e como adaptação de engenharia. $\mathrm{O}$ primeiro sentido refere-se apenas ao resultado dos processos seletivos. "Qualquer traço que emerge diretamente a partir de um processo seletivo é considera-

4. Note-se que, de acordo com Lloyd, isso não implica uma resposta à pergunta sobre o replicador, o qual, como acabamos de ver, pode ser distinto do gene. 
do, por definição, uma adaptação" (Lloyd, 2007, p. 52). Mais concretamente, podemos definir uma adaptação, nesse sentido, como o simples incremento da aptidão (fitness) diferencial de um interatuante em detrimento de outro. O segundo sentido aplica-se a traços que exibem características (morfológicas ou comportamentais) "bem-sucedidas" em relação a um determinado ambiente. Já citei, como exemplos, o maior tamanho, as asas ou as garras, aos quais podemos acrescentar as técnicas de acasalamento ou de caça. Williams requer que, para que exista seleção de grupo, devem-se dar dois fatores: (1) que o grupo seja um interatuante, (2) que exista uma adaptação de engenharia no nível do grupo. A falta de (2), característica do nível dos organismos, prejudicaria a plausibilidade de (1). Contudo, segundo Lloyd, não é evidente que o segundo requisito seja necessário. Embora, talvez, apenas as adaptações de engenharia sejam adaptações em sentido próprio (cf. Brandon, 1978; Mills \& Beatty, 1979), para que possamos dizer que existem pressões seletivas no nível do grupo (e de qualquer outro interatuante) é suficiente postular, nesse nível, adaptações como produto da seleção. Ao longo do artigo, mostrar-se-á que adaptações como produto da seleção no nível do grupo existem e que, de alguma maneira, é só graças a elas que certas adaptações de engenharia podem manifestar-se no nível dos organismos, por exemplo, como no caso dos peixes guppy (cf. p. 109 abaixo).

Resumindo, admitimos os seguintes pressupostos:

- Existem entidades, em vários níveis de complexidade biológica, que podem funcionar como replicadores, isto é, transmitem diretamente uma estrutura ao longo das gerações.

- Os replicadores são selecionados apenas indiretamente, por meio da ação que o ambiente exerce sobre o fenótipo dos interatuantes.

- Existem distintos níveis de interatuantes (organismos, grupos, espécies etc.).

- Os processos seletivos favorecem comportamentos que não resultam necessariamente em adaptações de engenharia no nível dos interatuantes, mas isso não representa uma limitação na hora de aceitar a seleção de grupo.

As duas questões que esboçamos a partir de Reeve e Keller (1999) podem ser agora formuladas de maneira mais contextualizada:

(1) Quais mecanismos, e em que nível, fazem que um grupo funcione como interatuante?

(2) Como são distribuídas, e como se manifestam, em uma população humana complexa, as forças seletivas sobre diferentes interatuantes? 


\section{O paradoxo de Simpson}

\section{E A POSSIBILIDADE DO ALTRUÍSMO GOMO TRAÇO INTERATUANTE}

Brandon, assim como outros autores da corrente pluralista (cf. Sober, 1984, 1993; Hull \& Ruse, 1998), admite a possibilidade de que um grupo seja um interatuante, mas reconhecem também que os casos nos quais tal circunstância é verificável empiricamente não são frequentes. Tradicionalmente (cf. Darwin, 1985 [1859]; Wright, 1945; WynneEdwards, 1962), a testabilidade da hipótese tem sido associada à da existência de comportamentos altruístas (ainda que o altruísmo não seja a única adaptação que pode depender da seleção de grupo). O que significa isso? Na introdução, citei a definição de altruísmo dada por Haldane, que apontava as circunstâncias em que um organismo aporta um benefício a outro a suas expensas. Exemplos de comportamentos altruístas frequentemente citados na literatura são as abelhas que atacam invasores da colmeia com o próprio ferrão, morrendo no ato (cf. Darwin, 1985 [1859]), os macacos que avisam seus parceiros quando avistam um leopardo, arriscando a própria vida (cf. Hauser, 1996), ou os morcegos-vampiros que compartilham o sangue obtido com os membros de seu grupo (cf. Wilkinson, 1990). Trata-se de comportamentos não adaptativos para o organismo (em graus distintos, obviamente), já que podem prejudicar seriamente sua aptidão e, até os anos 1960, não parecia plausível que pudessem ter sido selecionados individualmente. Evocava-se então a existência de um mecanismo de alto nível como o instinto de sobrevivência da espécie (cf. Lorenz, 1963) ou o controle da taxa de natalidade (que evitaria a superpopulação tramite o sacrifício de algum indivíduo), os quais agiriam seletivamente sobre grupos inteiros. Wynne-Edwards acreditava que o egoísmo generalizado fosse inviável, já que produziria um esgotamento dos recursos naturais que levaria a população à extinção. Para ele, se um grupo no qual os membros se comportam altruisticamente obtém um benefício global maior que um grupo composto por indivíduos egoístas, então teríamos um caso confirmado de seleção de grupo e da existência de mecanismos reguladores nesse nível.

Os adversários dessa perspectiva (cf. Hamilton, 1963; Maynard-Smith, 1964; Williams, 1966; Lack, 1966; Trivers, 1971; Wilson, 1975; Dawkins, 1976) não negavam a existência de comportamentos altruístas, mas criticavam a tese de que sua difusão fosse devida a mecanismos específicos de seleção de grupo. Para esses autores (todos mais ou menos próximos à área da sociobiologia), não faz sentido pensar na seleção natural como um mecanismo que age entre coletividades (no nível interdêmico), mas apenas dentro delas (no nível intradêmico). Adotando mais uma vez a terminologia de Dawkins, o altruísmo, assim como qualquer outro traço fenotípico exibido pelo veículo/interatuante (o organismo), depende causalmente da seleção que atua sobre os replicadores genéticos. Sendo estes últimos intrinsecamente egoístas, o altruísmo 
mostrado pelo interatuante deve ser de alguma maneira aparente, para poder evoluir. Embora ele seja vantajoso também para outro parceiro, na verdade incrementa principalmente a aptidão dos replicadores do indivíduo.

A partir desses pressupostos, o fenômeno do altruísmo no reino animal foi tratado como a manifestação de dois mecanismos agentes no nível do replicador, a seleção de parentesco (cf. Hamilton, 1963, 1964,a, 1964,b) e o altruísmo recíproco (cf. Trivers, 1971). O primeiro consiste em um mecanismo evolutivo que induz os organismos a defender a prole dos parentes mais próximos (com os quais compartilham parte da dotação genética, pela primeira lei de Mendel), além da própria, com a finalidade de maximizar a chamada aptidão inclusiva. Isso explicaria, por exemplo, o comportamento da abelha que, como muitos Hymenoptera, possui um sistema de determinação sexual haplodiploide (as irmãs compartilham $3 / 4$ da carga genética). O sacrifício de uma fêmea em defesa da colmeia não representa um comportamento desinteressado, mas dirigido à otimização da aptidão do núcleo parental (e, portanto, de certos replicadores). O altruísmo recíproco, por outro lado, é uma dinâmica pela qual os indivíduos ajudam um parceiro com a previsão de obter em troca um benefício para si. Esse tipo de altruísmo seria comum, por exemplo, entre os morcegos-vampiros, os quais precisam de uma refeição a cada, ao menos, dois dias para poder sobreviver, e as condições de caça são frequentemente desfavoráveis. Compartilhar sangue com outro membro do grupo assegura um potencial aliado no futuro. O comportamento altruísta representa aqui o melhor cálculo egoísta, a longo prazo.

Embora seja verdade que muitos casos de seleção de grupo são descritíveis em termos de modelos de seleção individual ou de parentesco, isso não justifica a adoção incondicional da interpretação reducionista. Sober e Wilson (1994, 1998; a partir da equação de Price e do artigo de Hamilton de 1975) 5 mostraram que a ideia de que o grupo seja um interatuante que compete com outros grupos pode dar conta não somente dos fenômenos da seleção de parentesco e do altruísmo recíproco, mas também de outros comportamentos altruístas que resultam inexplicáveis na perspectiva reducionista. O ponto de partida de Sober e Wilson é que qualquer conjunto de organismos que compartilha um mesmo "destino" evolutivo pode, em princípio, consti-

5 Hamilton, inicialmente condicionado pelo ambiente acadêmico hostil à possibilidade da seleção de grupo, concebeu a seleção de parentesco como um caso de seleção individual (a noção de "aptidão inclusiva” implica, de fato, uma extensão do egoísmo do organismo ao núcleo parental). O encontro com George Price - nas palavras de Sober e Wilson (1998, p. 53), "um estadunidense enigmático, que Hamilton (1996, p. 26) descreveu como 'outro indivíduo solitário"” - mudou sua perspectiva. A equação de Price mostra que, ao calcular a frequência de um gene em populações formadas por grupos, é importante tomar em consideração tanto as pressões intradêmicas como as interdêmicas, já que ambos fatores podem influir no produto final. A partir dessas equações, Hamilton (1975) reformulará o modelo da seleção de parentesco em termos compatíveis com a seleção de grupo, chegando até a minimizar a importância do vínculo parental nas interações altruístas (1975, p. 138). 
tuir um interatuante. $\mathrm{O}$ destino comum é determinado pela presença de certos traços cujos efeitos adaptativos repercutem sobre o grupo como um todo, caracterizando assim o fenótipo do interatuante. Os traços relevantes para definir um interatuante não devem ser necessariamente possuídos por todos os membros do grupo, mas apenas por alguns deles. Como veremos em breve, o que é importante é que exibam certo efeito estatístico. Essa interpretação enfraquece ulteriormente os requisitos originários de Hull. Para ser um interatuante, é suficiente que o grupo tenha certa composição, e não precisa ser fisicamente conectado (como uma colônia) ou mutuamente coordenado (como uma colônia de Hymenoptera). Lembrem que, conforme as sugestões de Lloyd (2007), a caracterização do interatuante não implica uma afirmação sobre o manifestador da adaptação, o qual, dependendo da situação específica, bem pode ser o gene ou o organismo. A questão é que, diversamente do que preveem os modelos reducionistas, não somente o egoísmo é adaptativo. Quando um interatuante coletivo é visível à seleção natural, é certo exatamente o contrário e os organismos altruístas são geralmente os mais favorecidos.

$\mathrm{O}$ argumento proposto para sustentar a tese de que existam traços suficientes a constituir um interatuante, cuja aptidão é distinta da média das aptidões individuais dos organismos que formam parte dela, é elaborado a partir do que é conhecido como o paradoxo de Simpson. Tal paradoxo pode surgir, em estatística, quando se comparam tendências relevadas a partir da análise de dois ou mais grupos pertencentes a uma mesma população em separado e, sucessivamente, em conjunto. Em determinadas circunstâncias, observa-se que uma tendência que vale para cada grupo é invertida quando os grupos são comparados entre si. Isso é geralmente devido ao fato de que, ao determinar as tendências próprias de um grupo, não são considerados fatores relevantes no nível da população. Os reducionistas acreditam que o que é vantajoso para os genes será necessariamente vantajoso para qualquer nível biológico superior. Nessa perspectiva, um comportamento geneticamente egoísta favorece o indivíduo e, indiretamente, o grupo do qual forma parte mais que qualquer outro comportamento alternativo, em qualquer situação. Porém, a introdução de variáveis negligenciadas na análise comparativa de fenômenos adaptativos que abarcam populações compostas por grupos heterogêneos mostra que as coisas podem não ser assim.

Como vimos, os modelos reducionistas consideram que apenas as interações entre indivíduos do mesmo grupo (seleção intradêmica) têm relevância para os processos evolutivos, e ignoram os efeitos que poderia ter a interação entre grupos (seleção interdêmica). A esse propósito, Sober (1996 [1993], p. 170) considera que 
o paradoxo de Simpson surge quando duas propriedades $C$ e $E$ estão correlacionadas positivamente dentro de cada uma das subpopulações de um conjunto, $B_{1}, B_{2}, \ldots, B n$, mas não o estão na média de todas as subpopulações:

$$
\begin{gathered}
P(E / C \& B i)>P(E / \neg C \& B i), \text { para cada } i, \\
P(E / C) \ngtr P(E / \neg C) .
\end{gathered}
$$

Apresentando a questão de maneira levemente diferente de como faz Sober, podemos considerar $E$ como a propriedade de ter maior aptidão e $C$ como a propriedade de ter um comportamento egoústa (individualmente vantajoso). Pode-se dar, e de fato se dá, uma situação na qual o grupo $B$ r, composto por uma maioria de indivíduos $C i$, possua uma menor descendência que o grupo B2, cuja composição prevalente é $\neg C i$. Isso é intuitivamente possível pelo fato de que podem intervir outros fatores, como a aparição de uma propriedade $A$, ter um comportamento altruísta (coletivamente vantajoso), tal que

$$
\begin{gathered}
\forall x(A x \text { sse } \neg C x) \\
P(E / C \& B i)>P(E / A \& B i), \text { para cada } i ; \text { mas } \\
P(E / C \& B)<P(E / A \& B) .
\end{gathered}
$$

Note-se que $A$ é um traço fenotípico do grupo (nesse caso B2). Se não fosse assim, não seria possível considerar sua correlação positiva com $E$ nesse nível, já que a aptidão de $A i$, tomado individualmente, é sempre menor do que a de $\mathrm{Ci}$. A existência de traços fenotípicos de grupo desse tipo torna plausível a seleção interdêmica. Na desconsideração desse ponto consiste, justamente, o erro dos modelos tradicionais (a "falácia da média”, como a chama Sober). As propriedades fenotípicas, na perspectiva reducionista, são possuídas apenas por indivíduos e não por grupos, de maneira que seria teoricamente possível calcular as melhores estratégias comportamentais sem considerar esse nível seletivo superior. Contudo, se as coisas fossem realmente assim, ficariam sem explicar todos os casos nos quais a presença de $A i$ em $B_{2}$ garante a sobrevivência do grupo, enquanto a ausência em Br implica uma diminuição da aptidão ou, até mesmo, sua desaparição.

Considerem o caso seguinte (cf. Wickler, 1976). Dicrocoelium dendriticum é um parasita que transcorre o estado adulto de sua vida no fígado das vacas ou das ovelhas. Suas ovas são expulsas nas fezes desses animais e ingeridas por caracóis, no estômago dos quais desenvolvem-se até um estado larval. As larvas (cercarias) são ingeridas, a sua vez, junto com as fezes do caracol, pelas formigas que povoam os campos. No estômago das formigas acontece algo surpreendente. Em alguns casos, um dos parasitas migra até o gânglio subesofágico do inseto (seu cérebro) e, ali, forma um cisto conhecido como verme cerebral. $\mathrm{O}$ verme cerebral altera o comportamento da formiga, que 
passa mais tempo na ponta dos fios de erva do que no solo, tendo assim mais possibilidades de ser comida por uma vaca ou uma ovelha, no corpo das quais a colônia de D. dendriticum poderá continuar seu ciclo vital (cf. Sober \& Wilson, 1998, p. 3-4). ${ }^{6}$ Durante a última fase do processo o verme cerebral morre, sacrifica sua vida em favor dos outros membros do grupo. O dispositivo comportamental que faz com que um parasita se transforme em um verme cerebral é certamente de origem genética, mas isso não implica que a seleção esteja atuando diretamente sobre os genes. As colônias onde nenhum indivíduo possui o gene altruísta do verme cerebral têm uma aptidão global inferior à dos grupos onde esse gene está presente (já que têm menos possibilidades de ser transmitidas ao fígado do gado), embora a média das aptidões dos indivíduos do grupo egoísta seja estatisticamente maior à dos indivíduos do segundo grupo (a aptidão do verme cerebral é zero).

Para que possamos dizer de um grupo que é altruísta, é necessária, obviamente, certa manutenção do traço. Para que o grupo possa manter sua aptidão diferencial tem de existir, em cada geração, um ou mais indivíduos altruístas. Porém, aqui não trataremos a questão de como se mantém a frequência relativa dos genes altruístas dentro dos grupos (cf. Hamilton, 1975; Sober \& Wilson, 1994), mesmo porque, como veremos daqui a pouco, a recombinação genética não é o único fator que favorece a difusão do altruísmo. Assumiremos apenas que $A$ é um traço genuíno do grupo $B$ se e somente se o grupo, em $t n$, possui ao menos um indivíduo $A i$, cujo comportamento incrementa a aptidão de $B$, em seu conjunto, mais do que se $A i$ fosse ausente.

\section{Hierarquias de organização sogial: OS EFEITOS DA TRANSMISSÃO GULTURAL}

A larva de $D$. dendriticum que se torna verme cerebral não tem escolha, sua dotação genética "a obriga" a se sacrificar para o grupo. Da mesma maneira, os outros membros da colônia não têm possibilidade de escolher seus parceiros. Estar em um grupo formado por um potencial verme cerebral é uma questão de sorte. Outras espécies são evolutivamente "programadas" para poder adotar atitudes diferentes, quando assim

6 É importante notar que $D$. dendriticum se reproduz dentro do caracol assexuadamente, criando cópias idênticas, mas isso não permite a aplicação do modelo hamiltoniano da seleção de parentesco em sua forma tradicional. As colônias larvais que são transmitidas às formigas não têm necessariamente relações de parentesco, já que constituem grupos mistos, que contêm espécimes provenientes de distintas ovas. Isso significa que o verme cerebral não se sacrifica para os parentes, mas para um grupo aleatório (agradeço Charbel Niño El-Hani pela sugestão). Com relação ao modelo hamiltoniano, vale a pena assinalar (como Hamilton mesmo admitiu, ver a nota 5) que a seleção de parentesco é um subcaso da seleção de grupo, já que todo conjunto parental pode ser considerado como interatuante, no sentido de Hull. 
requerem as circunstâncias. Nesses casos, é possível observar uma certa tendência, por parte dos indivíduos, a formar parte de grupos com um maior número de altruístas. Sober e Wilson (1998, p. 115-6) citam os experimentos com peixes guppy (Poecilia reticulata) - ou barrigudinhos - de Dugatkin e Alfieri (cf. 1991a; 1991b), os quais exibem uma primitiva capacidade de mudar de comportamento com relação ao comportamento dos parceiros. Nessa espécie, o comportamento altruísta é calculado a partir da propensão de um indivíduo a se aproximar de um potencial predador. O indivíduo corre o risco de ser facilmente atacado, mas fornece ao cardume uma valiosa informação ambiental acerca de possíveis perigos. Obviamente, se o explorador fosse sempre o mesmo, sua "carreira" altruísta não seria muito longa e a vantagem de grupo desapareceria. É assim que, em $P$. reticulata, têm evoluído certas capacidades cognitivas para distinguir um bom parceiro (altruísta) de outro ruim (egoísta). Também evoluíram capacidades cognitivas manifestamente egoístas (as mais vantajosas, do ponto de vista reducionista); alguns indivíduos conseguem se "fingir" altruístas para ter melhores parceiros, sem assim assumir nenhum risco. Esses indivíduos "trapaceiros" conseguem enganar os outros membros do cardume por meio de "falsos riscos". Eles se aproximam de um possível predador, mas não tanto a ponto de poder resultar mortos por um eventual ataque.

Temos então, por um lado, uma pressão seletiva intradêmica (sobre organismos), que favorece os membros egoístas, cuja aptidão individual tem um valor médio superior (ainda mais se conseguirem se infiltrar em um grupo com membros altruístas) e, pelo outro, temos uma pressão seletiva interdêmica (sobre grupos), evidenciada pelo fato de que os grupos altruístas exibem uma aptidão global superior. Surge agora o problema de considerar como interagem essas pressões, qual é a predominante e qual é o comportamento que resulta mais adaptativo. ' Como vimos, os barrigudinhos podem, dentro de certos limites, escolher a que grupo pertencer, e é óbvio que a opção melhor é estar em um grupo altruísta. Mais exatamente, a melhor opção de todas, para um indivíduo altruísta, é estar em um grupo altruísta que não tenha membros egoístas, os quais se beneficiariam sem aportar nada ao grupo. Os experimentos de Dugatkin e Alfieri (1991b) mostram que, geralmente, os altruístas conseguem detectar os egoístas, os quais veem-se obrigados a formar grupos entre eles, tendo assim uma aptidão notavelmente reduzida. Esta é uma evidência a favor da predominância das pressões

7 Note-se que o modelo do altruísmo recíproco, ao qual esse caso poderia ser à primeira vista reduzido, não pode dar conta dos dois níveis nos quais as pressões seletivas estão agindo (cai na falácia da média). Assim como o modelo da seleção de parentesco, ele constitui uma simplificação e um subcaso da seleção de grupo. Temos um caso de altruísmo recíproco quando a presença de determinados traços não faz que o grupo seja um interatuante em um sentido interessante. Isto é, não faz que o grupo, considerado dentro de uma população maior (composta por outros grupos), manifeste a inversão de tendência, com respeito à analise dos indivíduos, requerida pelo paradoxo de Simpson. 
interdêmicas e da tese de que, ao menos no estado evolutivo atual, os comportamentos altruístas são tendencialmente mais adaptativos.

Dado esse exemplo, vamos então tratar o caso das sociedades humanas, de uma maneira levemente diferente de como fazem Sober e Wilson. De acordo com eles, se $P$. reticulata, com seu elementar sistema nervoso, conseguiu evoluir com comportamentos tão adaptados com respeito à seleção do altruísmo e à detecção dos egoístas, então podemos imaginar que os seres humanos devem também exibir algum mecanismo desse tipo, muito mais sofisticado. Na verdade, no caso do ser humano, a complexidade da interação entre indivíduos é dupla. Por um lado, ela é devida à presença de um conjunto de faculdades cognitivas, linguísticas e sociais cujas funções específicas são dificilmente identificáveis. Pelo outro, e como consequência dessa rede de habilidades, um distinto tipo de complexidade é dado pela capacidade humana de constituir estruturas sociais e hierarquias de interatuantes que não são imediatamente redutíveis às categorias empregadas até agora. Sober e Wilson concentram-se sobre o primeiro problema, que aqui comentarei brevemente, para logo me dedicar ao segundo.

Um elemento fundamental para o entendimento de ambas as questões é o fenômeno da transmissão cultural (cf. Cavalli-Sforza \& Feldman, 1981; Boyd \& Richerson, 1985; Durham, 1991; Richerson \& Boyd, 2006 [2005]; Jablonka \& Lamb, 2005). Este é definido de maneira distinta nos vários modelos citados, mas pode ser caracterizado genericamente como um processo de transmissão não genética de informações relevantes para o comportamento social, que Richerson e Boyd (2006 [2005]) chamam de "variantes culturais". As variantes culturais são elaboradas a partir de padrões de comportamento, representados cognitivamente, que estimulam os indivíduos a realizar uma determinada atividade. Elas são as "categorias simbólicas" dos comportamentos; convertem, por exemplo, o ato da circuncisão em um "pacto com Deus", o uso repetido de certas técnicas agrícolas na "rotação trienal de cultivos", a repetida confirmação de previsões em uma boa hipótese. As variantes culturais, embora existam apenas como crenças particulares, podem ser transmitidas de geração em geração, garantindo a acumulação de técnicas, conhecimentos e estratégias organizativas (cf. Baravalle, 2013, p. 126). Dadas essas premissas, é plausível considerar a transmissão cultural como um processo no qual o membro de uma comunidade é o replicador de informações comportamentais, e um certo conjunto de membros, identificado pela adesão aos padrões de comportamento implícitos em uma ou mais variantes culturais, é o interatuante.

Para Sober e Wilson (1998, cap. 4-5), essa intuição é reforçada pela observação do papel das normas sociais e das instituições, entendidas como promotoras e reguladoras das normas sociais, em várias sociedades. Estas, através de um sistema de prêmios e castigos, podem (entre outras coisas) incentivar os comportamentos altruístas e desestimular os comportamentos egoístas. O padrão de comportamento premiado 
ou castigado varia de sociedade a sociedade, mas, do ponto de vista estrutural, as normas sociais possuem algumas caraterísticas comuns. Em primeiro lugar, obviamente, estabelecem quais comportamentos são aceitos em um grupo e quais devem ser castigados. Em segundo lugar, incluem implicitamente a obrigação, para os membros do grupo, de fazer respeitar as normas, sob pena de serem castigados. Em terceiro lugar, e para favorecer sua própria difusão, implicam um gasto mínimo de energia por parte dos "castigadores" que, assim, são incentivados a desenvolver sua tarefa. Todo esse sistema de prêmios e castigos deveria (e de fato, em muitos casos, consegue) limitar o número dos egoístas que aproveitam os benefícios de um grupo altruísta.

Dentro de uma comunidade, uma pessoa pode agir alternativamente em seu próprio benefício, para ajudar seus parceiros mais próximos, um grupo social ou a comunidade inteira (cf. Maynard-Smith, 1999, p. 207-8). Em cada nível, e ampliando o número de pessoas envolvidas no comportamento, existem normas sociais (embora não existam instituições em sentido próprio em cada nível) e diferentes graus de altruísmo. Não necessariamente uma ação favorecerá todas essas coletividades, e as várias opções comportamentais poderão entrar em conflito entre si, já que um comportamento que favorece um grupo pode ser negativo para a comunidade em seu conjunto (frente a outras comunidades). Assumiremos aqui uma estrutura hierárquica na qual as famílias e os grupos sociais dentro da comunidade são mais ou menos definidos, por meio das normas sociais características, e constantes ao longo do tempo:

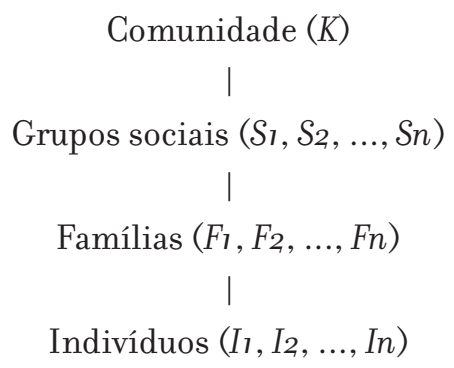

Assumiremos que $K$ é a comunidade inteira, o metagrupo de nível mais alto, o qual, contudo, pode eventualmente interatuar com outros metagrupos. No outro extremo, $F$ pode ser considerado como o primeiro nível de agrupação social. Conforme a caracterização dada anteriormente - ou seja, que o altruísmo é um traço fenotípico evolutivamente relevante de um grupo $B$ se e somente se o grupo, em $t n$, possui um ou mais indivíduos altruístas $A i$, cujo comportamento incrementa a aptidão de $B$, em seu conjunto, mais do que se $A i$ fosse ausente - $F$ é altruísta quando nele existe um número de $A i$ relevante do ponto de vista do incremento da aptidão do grupo. Analogamente, $S_{1}$ é altruísta se contém ao menos um $F$ altruísta que incrementa a aptidão diferencial em detrimento de $S_{2}$, que não contém $F$ altruístas. 
Supondo essa estrutura hierárquica de organização de grupos em níveis (a qual, obviamente, simplifica a estrutura real de uma sociedade, mas parece ser um modelo adequado para os estudos de referência citados), podemos observar que, dada uma pluralidade de possíveis comportamentos, um grupo pode ser altruísta em virtude dos comportamentos dos indivíduos que o compõem e, ao mesmo tempo, egoísta pelo papel que desenvolve dentro da comunidade. Isso é plausível em virtude da aplicação do paradoxo de Simpson ao nível dos metagrupos. É possível que, dados um comportamento egoísta $C$ e um altruísta $A$, o incremento da aptidão não esteja associado ao mesmo tipo de comportamento em todos os níveis, como de fato acontece quando analisamos a aptidão individual em comparação com aquela dos grupos.

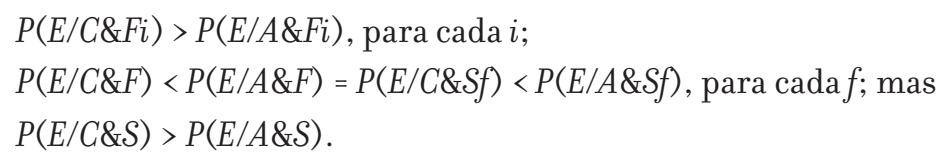

Um exemplo de situação desse tipo é estudado por Richerson \& Boyd (2006 [2005], p. 253-62; cf. Kraybill \& Olshan, 1994; Kraybill \& Bowman, 2001). Eles consideram o caso das famílias anabatistas dos amish e dos huteritas, as quais, mantendo uma tradição de colaboração mútua, manifestam uma taxa de crescimento populacional mais elevada em comparação com as famílias norte-americanas pertencentes a grupos sociais mais secularizados, com tendências individualistas. Contudo, ao comportamento altruísta interno aos grupos anabatistas não corresponde uma tendência altruísta também fora do grupo; os amish e os huteritas constituem microcomunidades fechadas que mantêm sua eficácia reprodutiva mediante a conservação dos recursos próprios e da exclusão dos não pertencentes à igreja. É evidente, nesse caso, que o papel das instituições e das normas sociais não é simplesmente o de regular a cooperação e incentivar o altruísmo dentro do grupo, mas também o de definir barreiras entre grupos, as quais são igualmente úteis para sua própria manutenção.

Ora, o incremento da aptidão dos anabatistas corresponde ao altruísmo das famílias ou ao egoísmo do grupo? Prima facie, diríamos que a ambos comportamentos, já que, ao fim e ao cabo, esses representam duas faces da mesma moeda. Isso sugere que, contrariamente ao que podia parecer em um primeiro momento, o papel evolutivo do altruísmo tem limites importantes dentro de uma organização social complexa. A cooperação dentro de um grupo, no caso dos anabatistas como em outros, parece ser eficaz apenas quando implica o egoísmo do grupo frente a outro, em certo nível da hierarquia social. Isso não implica, em minha opinião, uma ambiguidade sobre a caracterização do altruísmo anteriormente proposta; ao contrário, enriquece-a de um ulterior elemento. Os interatuantes altruístas podem manifestar comportamentos egoístas, e ser 
selecionados por esses comportamentos. O fato de que o sejam ou não depende, obviamente, das caraterísticas diferenciais da metapopulação à qual pertencem os interatuantes, e isso pode ser estabelecido só por meio de uma análise populacional, cujo método esboçaremos na última parte do artigo.

\section{4 “Bom” PARA QUEM? UMA PROPOSTA PARA A ANÁLISE EVOLUTIVA DOS GOMPORTAMENTOS ADAPTATIVOS EM SOGIEDADES GOMPLEXAS}

Acolhendo uma visão pluralista com respeito às unidades da seleção, o problema de individuar quais forças seletivas estão agindo em um caso concreto adquire uma dimensão complexa. ${ }^{\mathbf{8}}$ À primeira vista, o altruísmo parece ser uma estratégia comportamental "progressiva", no sentido de que, subindo na hierarquia da organização populacional, implica um benefício cada vez mais abrangente, para mais indivíduos. Todavia, vimos que não é necessariamente assim, já que nos níveis mais altos da estrutura social fica indeterminado se, para um interatuante, é mais adaptativo se comportar de uma maneira altruísta ou egoísta com respeito aos interatuantes do mesmo nível. Sober e Wilson (1994; 1998) sugerem uma estratégia em três passos para determinar, dado certo cenário evolutivo, em que nível agiriam as forças seletivas e que tipo de comportamento foi selecionado. Procederemos, portanto, a uma exposição crítica de cada passo, salientando a importância que eles têm em relação ao modelo hierárquico aqui apresentado.

O primeiro passo é a determinação do que evolui se a seleção de grupos for a única força evolutiva. Trata-se de um procedimento hipotético, já que na realidade, na maioria das circunstâncias, nunca atua uma única força evolutiva. Este seria o caso, idealizado, de $D$. dendriticum e dos interatuantes que consideramos como altruístas, frente a outros egoístas. A maior aptidão do grupo é, nesses casos, garantida pela contribuição altruísta dos membros (ou uma parte dos membros) do grupo. A maneira para estabelecer a importância dessa força é a de considerar um meio adaptativo (a defesa frente aos predadores, uma proporção equilibrada entre gêneros, a criação de instituições que garantam normas sociais etc.) para obter um incremento do aptidão, e conferir se os grupos altruístas são mais bem-sucedidos do que os grupos egoístas.

8 Sober e Wilson comparam a complexidade da análise das forças seletivas com a das forças na física. Imaginem uma bola empurrada em duas direções diferentes. "Se apenas nos importasse predizer a trajetória da bola, seria suficiente conhecer a resultante; mas não é suficiente se queremos compreender os processos que atuam. O paradoxo de Simpson demostra a confusão que aparece ao se centrar apenas nos resultados líquidos, e perder de vista os fatores causais componentes" (1998, p. 18). 
O segundo passo é a determinação do que evolui se a seleção de indivíduo for a única força evolutiva. Isso acontece, obviamente, em todos os casos nos quais não é aplicável o paradoxo de Simpson. Mais interessantes, neste contexto, são aqueles casos nos quais interatuantes como grupos são selecionados frente a outros grupos interatuantes, em virtude de um comportamento egoísta selecionado dentro de um metagrupo. Essa ampliação do domínio da seleção de indivíduos a grupos inteiros (não considerada por Sober e Wilson) é coerente com um outro aspecto da caracterização dos interatuantes discutido por Hull $(1980,1998)$. Para ele, o conceito de indivíduo pode ser aplicado a diferentes níveis de complexidade biológica, sem importar nossa preferência intuitiva para o nível dos organismos.

Os indivíduos são entidades, localizadas espaço-temporalmente, que têm inícios e fins razoavelmente nítidos no tempo (...), os elementos que compõem um indivíduo fazem-no pela maneira na qual são organizados e não porque compartem qualquer similaridade (Hull, 1980, p. 313).

Assim como o indivíduo pode ser um interatuante, um interatuante pode ser proveitosamente considerado como um indivíduo e, portanto, como sujeito a pressões interdêmicas, dentro de um hipotético metainteratuante (uma coletividade mais ampla). A maneira de avaliar a seleção a favor dos interatuantes nesse sentido é considerar se, dentro de uma metapopulação, as normas sociais - e as instituições que favorecem seu funcionamento - incentivam um comportamento coletivo egoísta (concentração dos recursos, exclusão dos infratores etc.) que garante um incremento diferencial da aptidão frente a outros interatuantes.

É evidente que também o segundo passo da análise representa uma idealização dos processos evolutivos que realmente influem sobre a composição demográfica de uma sociedade. De fato, tomando em consideração o caso dos amish e dos huteritas, seriamos tentados a dizer, por um lado, que a única força relevante para o incremento de sua aptidão é a coesão altruísta dos membros do grupo e, pelo outro, entendemos que não podemos ignorar, como fator relevante, seu encerramento conservador frente aos outros grupos. Assim, na análise das dinâmicas evolutivas dentro de uma sociedade, é extremadamente difícil, se não impossível, abstrair as circunstâncias para entender o que aconteceria se apenas uma das duas forças fosse presente. As duas forças parecem necessárias, mas, individualmente tomadas, não são suficientes para dar lugar ao fenômeno evolutivamente interessante.

Contudo, o terceiro passo fornece-nos indicações importantes sobre como calcular o valor relativo do egoísmo e do altruísmo em cada caso. Sober e Wilson (1998, p. 83) falam de "estudo dos componentes básicos da seleção natural em cada nível", 
para se referir a uma análise comparativa das forças seletivas atuantes nos diversos níveis de organização, obtida calculando a relevância dessas forças em cada um desses itens: (a) variação fenotípica entre as unidades (interatuantes); (b) herdabilidade; (c) diferenças na sobrevivência e na reprodução que correspondem a diferenças fenotípicas. Vamos ver, mais uma vez, de que maneira pode ajudar-nos, no presente contexto, o trabalho desses autores.

Em relação com o item (a), o que é requerido é uma análise da composição populacional em cada nível de organização, dirigida a calcular o grau de diferença entre um grupo e outro. Se, por exemplo, os grupos que constituem o mesmo metagrupo com os anabatistas apresentam normas sociais parecidas a esse grupo (caraterizadas, a saber, por uma forte concentração dos recursos e pela rígida exclusão dos que não compartilham o código religioso) e, todavia, existe uma diferença na aptidão relativa dos grupos, então é provável que as pressões seletivas estejam agindo principalmente entre os grupos, em virtude de sua composição mais ou menos altruísta, conforme a predição feita no primeiro passo. Ao contrário, se todos os grupos apresentam, mais ou menos no mesmo grau, comportamentos altruístas no próprio interior, mas as normas sociais incentivam comportamentos coletivos egoístas com relação aos outros grupos, então teremos que centrar nossa atenção na variabilidade dentro do metagrupo superior, conforme o tipo de seleção individual sugerido no segundo passo.

O item (b) enriquece a análise comparativa com a dimensão histórica. Para determinar se um fenômeno é realmente adaptativo ou, ao contrário, o incremento da aptidão se deve a circunstâncias evolutivamente não relevantes e não se manterá ao longo das gerações seguintes, é importante considerar o processo que tem levado o interatuante à atual composição populacional predominante e ao comportamento que expressa frente aos outros interatuantes. Conforme a terminologia aqui empregada, para avaliar o peso das pressões adaptativas em cada nível, devemos considerar se as caraterísticas populacionais evoluíram ao longo do tempo em direção a uma fixação de comportamentos egoístas ou altruístas - conferindo, por exemplo, se existem, e desde quando, instituições e normas sociais que favorecem ou obstaculizam a difusão desses comportamentos -, e verificar se, a tal tendência, corresponde um incremento de aptidão.

Obviamente, determinar o peso real das tendências históricas é mais complicado do que isso, e envolveria uma discussão mais aprofundada sobre o papel dos organismos e dos grupos como replicadores fiéis da informação cultural. Se esse requisito não for satisfeito, dificilmente poderíamos falar de uma transmissão hereditária genuína. O problema não parece de fácil solução, já que, no caso dos genes, conhecemos o mecanismo de replicação com um grau de detalhe bastante alto, enquanto no caso dos organismos ou dos grupos não é claro como deveria ser transmitida a estrutura relevante para a manutenção de um traço, na ausência de unidades discretas que in- 
corporem o processo. Já vimos como Richerson e Boyd (2006 [2005]), por exemplo, sugerem que as variantes culturais poderiam desenvolver essa função. Cavalli-Sforza e Feldman (1981) concordam com esses autores sobre o fato de que seja preciso encontrar uma unidade básica da transmissão cultural, enquanto Jablonka e Lamb (2005) negam que isso seja necessário ou até possível. Em minha opinião, independentemente da perspectiva particular, todos esses autores (e outros; cf. Durham, 1991; Bohem, 1993, 1996; Maynard-Smith, 1999) têm mostrado bastante convincentemente que podemos falar de herança cultural, apesar de não sermos capazes de encontrar entidades perfeitamente análogas aos genes. Se o requisito fundamental para ser um replicador é ser "uma entidade que transmite diretamente sua estrutura", então não vejo dificuldade em dizer que ele é, ao menos parcialmente, respeitado pelos membros de uma comunidade que compartilha linguagens, técnicas e valores.

O resultado conclusivo aportado pelo item (c) consiste na síntese dos dois fatores anteriores. Apenas quando é presente uma variação que se herda de um comportamento é possível considerá-lo adaptativo, diferencialmente vantajoso em comparação com outros. No modelo em múltiplos níveis, deveríamos atribuir mais relevância aos fatores que caracterizam um interatuante como altruísta quando a análise histórica indica que houve uma institucionalização dos comportamentos cooperativos internos a ele. Assim, quando entre dois grupos igualmente fechados entre eles, observamos uma diferença de aptidão, temos que procurar, dentro do grupo com aptidão maior, alguma norma social que contribuiu para incentivar os comportamentos altruístas. Ao contrário, deveríamos atribuir mais importância às pressões seletivas individuais que operam dentro do metainteratuante de nível superior quando, embora os interatuantes sejam semelhantes com relação à própria composição interna, é observada uma diferença de aptidão relevante. Nesse caso, deveríamos procurar alguma norma social que favoreceu o egoísmo de um interatuante frente aos demais do mesmo nível.

\section{Conclusão}

Neste artigo, tratei de aplicar a discussão sobre a seleção de grupo, com particular atenção à possibilidade de considerar os comportamentos altruístas como adaptativos, às sociedades humanas, organizadas hierarquicamente em uma estrutura que exibe vários níveis de interatuantes. Adotei uma perspectiva pluralista (frente à perspectiva centrada no gene egoísta) e apoiei-me, em especial, na proposta de Sober e Wilson (1994, 1998). Tentei encontrar uma resposta a duas perguntas, a saber, 
(1) quais mecanismos, e em que nível, fazem que um grupo funcione como interatuante?

(2) Como são distribuídas, e como se manifestam, em uma população humana complexa, as forças seletivas sobre diferentes interatuantes?

Com relação a (1), mostrei que o grupo pode ser considerado como interatuante quando existem traços fenotípicos, como o altruísmo, cuja vantagem adaptativa não pode ser analisada a partir dos organismos tomados singularmente. Para poder dar conta dos processos seletivos dentro de uma população composta por dois ou mais grupos, é preciso comparar as pressões intradêmicas com as pressões interdêmicas. $\mathrm{O}$ altruísmo representa um traço de grupo cuja presença implica, em muitos casos, um incremento de aptidão, por parte dos membros do grupo, maior do que caberia esperar se a única força evolutiva fosse a seleção individual.

Com relação a (2), vimos que nem sempre é possível estabelecer qual é a pressão evolutiva predominante, nem qual é o comportamento mais adaptativo. Em uma população complexa, como é o caso das populações humanas, os membros de uma comunidade costumam se encontrar em situações nas quais a pertença a um grupo implica também a pertença a um metagrupo, e assim por diante. $\mathrm{O}$ fato de que um grupo constitua um interatuante altruísta - conforme as condições estabelecidas por (1) não implica que o comportamento de um interatuante, frente a outros interatuantes, seja altruísta. Ao contrário, cabe esperar que a vantagem adquirida por meio de comportamentos altruístas seja equilibrada por um comportamento egoísta do grupo, considerado como indivíduo coletivo, frente a outros. Qual das duas pressões seletivas, se a interdêmica altruísta ou a intradêmica egoísta (nos vários níveis), seja a predominante é uma questão de estudo empírico, a ser desenvolvida de acordo com as sugestões dadas na seção 4 .ศ

Agradecimentos. Agradeço à Fundação de Amparo à Pesquisa do Estado de São Paulo (Fapesp/Brasil) pelo suporte e pelo financiamento de meu projeto de pesquisa "Estratégias cognitivas e evolução humana" (Processo 2010/178627), do qual este artigo faz parte.

\section{Lorenzo Baravalle}

Centro de Ciências Naturais e Humanas,

Universidade Federal do ABC, Brasil.

lorenzo_baravalle@yahoo.it

The many faces of altruism: selective pressures and human groups 


\begin{abstract}
In the debate on the units of selection, the controversy about the possibility of genuinely altruistic behavior has a prominent place. By assuming a pluralistic position, some relevant issues on the topic will be discussed in this paper. Firstly, altruism will be conceived as a phenotypic property of biological groups, not just of their members. Secondly, this characterization will be applied to the discussion on the relationship between groups in complex societies, as humans ones. In that context, a model about how altruistic and egoistic behaviors overlap at different levels of social dynamics will be outlined. Finally, a method aimed at determining what kinds of evolutionary forces influence behavior in empirical cases will be suggested.
\end{abstract}

KeYwords $\bullet$ Egoism. Altruism. Interactors. Unities of selection. Populations.

\title{
REFERÊNGIAS BIBLIOGRÁFIGAS
}

BARAVAlle, L. La venganza de Wilson. Una crítica a los enfoques seleccionistas analógicos de la evolución cultural. Diánoia, 58, 70, p. 111-3o, 2013.

Blackmore, S. The meme machine. Oxford: Oxford University Press, 1999.

Bовнм, C. Egalitarian society and reverse dominance hierarchy. Current Anthropology, 34, p. 227-54, 1993. Emergency decisions, cultural selection mechanics and group selection. Current Anthropology, 37, p. $763-93,1996$.

Boyd, R. \& Righerson, P. Culture and the evolutionary process. Chicago: University of Chicago Press, 1985.

Brandon, R. N. Adaptation and evolutionary theory. Studies in History and Philosophy of Science, 9, p. 181$206,197^{8}$.

Concepts and methods in evolutionary biology. Cambridge: Cambridge University Press, 1996.

Cavalli-Sforza, L. \& Feldman, M. Cultural transmision and evolution: a quantitative approach. Princeton: Princeton University Press, 1981.

Cohen, R. S.; Hilpinen, R. \& Renzong, Q. (Ed.). Realism and anti-realism in the philosophy of science. Dordrecht: Kluwer, 1996.

Darwin, C. R. A origem das espécies. São Paulo: Itatiaia, 1985 [1859].

Dawkins, R. The selfish gene. Oxford: Oxford University Press, 1976. The extended phenotype. Oxford: Freeman, 1982.

Dennett, D. C. Darwin's dangerous idea. New York: Simon \& Schuster, 1995.

Diéguez, A. La vida bajo escrutinio. Barcelona: Biblioteca Buridan, 2012.

Dugatkin, L. A. \& Alfieri, M. Tit-for-Tat in Guppies (Poecilia reticulata): the relative nature of cooperation and defection during predator inspection. Evolutionary Ecology, 5, p. 300-9, 1991 .

Guppies and the tit for tat strategy: preference based on past interaction. Behavioral Ecology and Sociobiology, 28, p. 24,3-6, 1991b.

Durham, W. H. Coevolution: genes, culture and human diversity. Palo Alto: Stanford University Press, 1991.

Fox, R. (Ed.). Biosocial anthropology. New York: John Wiley, 1975.

Haldane, J. B. S. The causes of evolution. London: Longmans, 1932.

Hamilton, W. D. The evolution of altruistic behavior. American Naturalist, 97, p. 354,-6, 1963. . The genetical evolution of social behavior I. Journal of Theoretical Biology, 7, p. 1-16, 1964,a.

The genetical evolution of social behavior II. Journal of Theoretical Biology, 7, p. 17-52, 1964,b.

Innate social aptitudes of man: an approach from evolutionary genetics. In: Fox, R. (Ed.). Biosocial anthropology. New York: John Wiley, 1975. p. 133-55.

The narrow roads of gene land. Oxford: Freeman/Spektrum, 1996. 
Hauser, M. D. The evolution of communication. Cambridge: The MIT Press, 1996.

Hull, D. Individuality and selection. Annual Review of Ecology and Systematics, 11, p. 311-32, 1980.

Sujetos centrales y narraciones históricas. In: Martínez, S. \& Barahona, A. (Ed.). Historia y explicación en biología. México: Fondo de Cultura Económica, 1998. p. 247-74.

HulL, D. L. \& Ruse, M. (Ed.). Philosophy of biology. Oxford: Oxford University Press, 1998.

The Cambridge companion to the philosophy of biology. Cambridge: Cambridge University Press, 2007.

Jablonka, E. \& Lamb, M. J. Evolution in four dimensions. Boston: The MIT Press, 2005.

Keller, L. (Ed.). Levels of selection in evolution. Princeton: Princeton University Press, 1999.

Kraybill, D. B. \& Bowman, G. F. On the backroad to heaven. Old order Hutterites, Mennonites, Amish, and

Brethren. Baltimore: Center for American Places, Books in Anabaptist Studies/Johns Hopkins University Press, 2001.

Kraybill, D. B. \& Olshan, M. A. The Amish struggle with modernity. Hanover: University Press of New England, 1994.

LaCK, D. Population studies of birds. Oxford: Oxford University Press, 1966.

Lewontin, R. G. The units of selection. Annual Review of Ecology and Systematics, 1, p. 1-18, 1970.

LLoyd, E. A. The structure and confirmation of evolutionary theory. Princeton: Princeton University Press, 1994.

. Units and levels of selection. In: Huld, D. L. \& Ruse, M. (Ed.). The Cambridge companion to the philosophy of biology. Cambridge: Cambridge University Press, 2007. p. 44,-65.

Lorenz, K. On aggression. London: Methuen Publishing, 1963.

Martínez, S. \& Barahona,A. (Ed.). Historia y explicación en biología. México: Fondo de Cultura Económica, 1998.

MaYnard-Smith, J. Group selection and kin selection. Nature, 210, p. 1145-6, 1964.

Conflict and cooperation in human societies. In: KeLLER, L. (Ed.). Levels of selection in evolution.

Princeton: Princeton University Press, 1999. p. 197-208.

Mills, S. \& Beatty, J. The propensity interpretation of fitness. Philosophy of Science, 46, p. 263-86, 1979.

Munz, P. Philosophical darwinism. London: Routledge, 1993.

ReEve, H. K. \& KeLLer, L. Levels of selection: burying the units-of-selection debate and unearthing the crucial new issues. In: KeLLER, L. (Ed.). Levels of selection in evolution. Princeton: Princeton University Press, 1999. p. 3-14.

Righerson, P. J. \& Boyd, R. Non di soli geni. Come la cultura ha trasformato l'evoluzione umana. Torino: Codice Edizioni, 2006 [2005].

Ridley, M. Evolution. Cambridge: Blackwell, 2004.

Shanahan, T. Realism and antirealism in evolutionary biology. In: Cohen, R. S.; Hilpinen, R. \& Renzong, Q. (Ed.). Realism and anti-realism in the philosophy of science. Dordrecht: Kluwer, 1996. p. 449-66.

Sober, E. The nature of selection. Chicago: The University of Chicago Press, 1984. Filosofia de la biología. Madrid: Alianza Editorial, 1996 [1993].

Sober, E. \& Wilson, D. S. El comportamiento altruista. Evolución y psicología, Madrid: Siglo Veintiuno, 2000 [1998].

Sterelny, K. \& Kitcher, P. The return of the gene. Journal of Philosophy, 85, p. 339-61, 1988.

Trivers, R. L. The evolution of reciprocal altruism. The Quarterly Review of Biology, 46, p. 35-57, 1971.

WICKLER, W. Evolution-oriented ethology, kin selection, and altruistic parasites. Zeitschrift für Tierpsycologie, 42, p. 206-14, 1976.

Williams, G. G.Adaptation and natural selection: a critique of some current evolutionary thought. Princeton, Princeton University Press, 1966.

WiLkinson, G. Food sharing in vampire bats. Scientific American, 262, 2, p. 64,-70, 1990. 
Wilson, D. S. \& Sober, E. Reintroducing group selection to the human behavioral sciences. Behavioral and Brain Sciences, 17, p. 585-654, 1994 .

Wilson, E. O. Sociobiology: the new synthesis. Cambridge: Harvard University Press, 1975.

Wright, S. Tempo and mode in evolution: a critical review. Ecology, 26, p. 4115-6, 1945 . . Genic and organismic evolution. Evolution, 34, p. 825-43, 1980.

Wynne-EDwards, V. C. Animal dispersion in relation to social behavior. Edinburg: Oliver and Boyd, 1962.

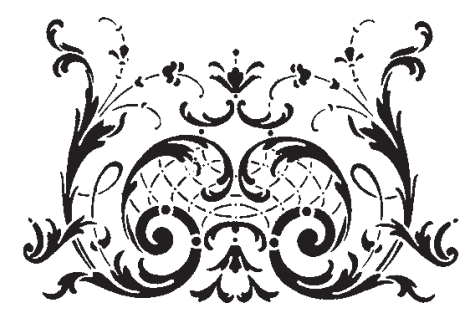

